\title{
Effect of Therapeutic Group Education on Adherence and Blood Pressure Control among Uncontrolled Hypertensive Patients in Sub Saharan Africa
}

\author{
Chris Nadège Nganou-Gnindjio ${ }^{1,2 *}$, Héloïse Guidelle Kenmogne Domning3, \\ Liliane Mfeukeu-Kuate1,2, Bâ Hamadou, 1,2, Félicité Kamdem,5, Georges Bediang1, \\ Aurel T. Tankeu1, Alain Patrick Menanga ${ }^{1,6}$, Samuel Kingue ${ }^{1,6}$

\footnotetext{
${ }^{1}$ Faculty of Medicine and Biomedical Sciences, University of Yaounde I, Yaounde, Cameroon

${ }^{2}$ Cardiology Unit, Yaounde Central Hospital, Yaounde, Cameroon

${ }^{3}$ Faculty of Health Sciences, Université des Montagnes, Bangangté, Cameroon

${ }^{4}$ Faculty of Medicine and Pharmaceutical Sciences, University of Douala, Douala, Cameroon

${ }^{5}$ Internal Medicine Department, Douala General Hospital, Douala, Cameroon

${ }^{6}$ Internal Medicine Department, Yaounde General Hospital, Yaounde, Cameroon

Email: *cn_nganou@yahoo.fr
}

How to cite this paper: Nganou-Gnindjio, C.N., Domning, H.G.K., Mfeukeu-Kuate, L., Hamadou, B., Kamdem, F., Bediang, G., Tankeu, A.T., Menanga, A.P. and Kingue, S. (2018) Effect of Therapeutic Group Education on Adherence and Blood Pressure Control among Uncontrolled Hypertensive Patients in Sub Saharan Africa. World Journal of Cardiovascular Diseases, 8, 183-195.

https://doi.org/10.4236/wjcd.2018.83018

Received: January 30, 2018

Accepted: March 24, 2018

Published: March 27, 2018

Copyright ( $\odot 2018$ by authors and Scientific Research Publishing Inc. This work is licensed under the Creative Commons Attribution International License (CC BY 4.0).

http://creativecommons.org/licenses/by/4.0/ c) (i) Open Access

\begin{abstract}
Background: Hypertension is the leading cardiovascular risk factor worldwide, with the greatest burden in low-income settings. Blood pressure (BP) control is usually low resulting in high rates of uncontrolled patients and complications. Low awareness resulting in poor therapeutic adherence represents an important factor for insufficient blood pressure control in developing countries. Methods: This was a three months non-randomized control trial at the cardiology clinic of the Yaoundé Central Hospital. We included adults with essential and uncontrolled hypertension. The intervention consisted of group educative sessions every week focusing on knowledge of hypertension risk factors, complications, treatment, comorbidities, home self-monitoring of BP. Home blood pressure figures, drug compliance, and knowledge regarding hypertension were evaluated before and after. Results: 17 participants ( 8 women) with a mean age $56.2 \pm 8.1$ years. During intervention, mean SBP decreased by $30 \mathrm{mmHg}$ while mean DBP drooped by $11 \mathrm{mmHg}$ using home BP measures. Knowledge regarding hypertension, adherence and drug compliance increased by $36.5 \%$, $88.2 \%$ and $81.4 \%$ respectively. Conclusion: Therapeutic group education resulted in a significant improvement in BP control amongst uncontrolled hypertensive patients in sub Saharan Africa.
\end{abstract}


Keywords

Therapeutic Group Education, Hypertension, Adherence, Knowledge

\section{Introduction}

High blood pressure is a major public health threat affecting nearly $40 \%$ (about one billion) of adults worldwide [1]. It is by far the leading cardiovascular risk factor responsible for 7\% of the years lost life and 9.4 million deaths [2]. In 2010, hypertension was responsible for more than 500,000 deaths, 10 million years of life lost and alone accounted for about $7.3 \%$ of total health care expenditures [3] [4] [5]. More than $80 \%$ of the global burden of high blood pressure weighs on low- and middle-income countries [6]. Africa presents the highest prevalence of hypertension, where $46 \%$ of adults over 25 years of age are affected by the disease amongst which $66 \%$ of patients are unaware of their condition and $82 \%$ are untreated [1] [5]. Moreover, despite increasing efforts and the multiple treatment modalities available today, the proportion of uncontrolled hypertensive individuals have increased from 605 million in 1980 to 978 million in 2008 [3]. This situation is even worst in Africa where about 93\% of treated patients do not reach the targets [1] [5]. This has been attributing to a low adherence and lack of compliance of patients to pharmacological and non-pharmacological treatment in our context [7]. Therefore, improving treatment adherence and patient compliance could increase hypertension control and reduce the total burden of this condition. This has been suggested by some studies which showed that raising adherence to therapeutic recommendations is associated with better BP control [8]. The aim of this study was to investigate the effect of therapeutic group education on adherence and blood pressure control in uncontrolled hypertensive patients in Cameroon, sub Saharan Africa.

\section{Material and Methods}

\subsection{Ethical Considerations}

This study was carried out in accordance with the Declaration of Helsinki, and was approved bythe Institutional Research Ethical Committee of Université des Montagnes ( $\mathrm{N}^{\circ} 2017 / \mathrm{o} 28 / \mathrm{UdM} / \mathrm{PR} / \mathrm{CIE}$ ), and by the institutional review board of the Yaoundé Central Hospital of Cameroon. This project was also approved by the regional ethic committee of the central region of Cameroon Identifier (No.: 0551/CRERSHC/2016). All participants provided written informed consent.

\subsection{Study Design and Setting}

This was a non-randomized controlled trial carried out from October 2016 to June 2017 at the outpatient cardiology clinic of the Yaoundé Central Hospital, a tertiary center of Yaoundé, Capital of Cameroon. 


\subsection{Participants}

We included adults with essential, uncontrolled hypertension (systolic blood pressure $\geq 140 \mathrm{~mm} \mathrm{Hg}$ and/or diastolic blood pressure $\geq 90 \mathrm{~mm} \mathrm{Hg}$ ) according to international guidelines (JNC8 and WHO 2010) [1] [9], on any stable antihypertensive therapy for at least 3 months, non-observant to therapeutic measures who consent to participate. Patients with chronic pathology other than high blood pressure (diabetes, gout, heart failure, renal insufficiency, dementia, asthma, Parkinson's disease, epilepsy, cancer, and chronic obstructive pulmonary disease) as well as pregnant and/or breastfeeding women were not included. Exclusion criteria consisted of individuals presenting acute complications of high blood pressure such as stroke, MI or elevated BP over 180/110 mm $\mathrm{Hg}$ during the study. Patients whose antihypertensive treatment was changed or modified during the study and those attending less than 10 therapeutic education sessions out of the 12 were also excluded.

\subsection{Outcome}

Our primary outcome was the difference in adherence scores before and after intervention. Secondary outcome measures were: improvement in blood pressure and the improvement of knowledge concerning BP and its treatment as well as pre- and post-intervention physical activity levels.

\subsection{Sample Size}

The sample size was calculated using Whitley's formula: $\mathrm{N}=2 \mathrm{Cp}$, power $/ \mathrm{d}^{2}$ where $\mathrm{N}$ = sample size, $\mathrm{Cp}$, power $=$ constant defined by the values of $\mathrm{p}$ (threshold of significance) chosen available in the statistical tables [10]. For a value of $\alpha=0.05$ and a power of $95 \%, \mathrm{cp}$, power $=13 . \mathrm{D}=$ expected difference/standard deviation. We hypothesized a variation of the adherence score of about $25 \%$ compared to that obtained before our intervention. Given that the mean score obtained in the study for the validation of the 8-item Morisky questionnaire was 6.96 with a standard deviation of 1.25 [11]. The minimum sample size was therefore estimated at 14 patients.

\subsection{Data Collection and Procedure}

After recruitment of eligible patients, we carried out an initial evaluation based on socio-demographic, anthropometric parameters, clinical and home blood pressure figures, history of hypertension, drug compliance, and knowledge concerning hypertension and other cardiovascular risk factors, level of physical activity, quality of food and stress in the working environment. These data served as baseline characteristics.

Then, the working materials were given to each patient namely; electronic home blood pressure devices, pedometers, educative materials and follow-up cards. Under the supervision of a cardiologist and a dietician, we carried out group patient education that consisted of lessons focusing on knowledge of risk factors 
for hypertension, complications, treatment, comorbidities, home self-monitoring of BP, quality of food, drug adherence, alcohol consumption, tobacco and stress. These lessons were carried out in the form of standard lecture followed by group discussion and quizzes with answers. The follow-up was done using regular phone calls and daily text messages that were sent to remind each patient of their medication, blood pressure monitoring, dietary measures and subsequent appointments. The patient recorded on follow-up cards home blood pressure figures, names, dose and number of medications taken per day and hours, pedometer data during physical activity, alcohol consumption, and cigarette smoking. In addition, follow-up was carried out once a week at the hospital. During the re-evaluation sessions, patients exchanged personal experiences with their illnesses, difficulties encountered in daily compliance with the recommendations given during therapeutic education, and with the help of the cardiologist and dietician we discussed to find solutions adapted to their needs.

Re-evaluation was done three months after the beginning of intervention and focused on characteristics measured at baselines especially medication adherence, level of knowledge, quality of feeding and level of satisfaction with education received during the study. Therapeutic education was defined as a continuous, integrated, patient-centered process, including organized awareness, information, learning and psychosocial support activities related to disease, prescribed treatment, care and hospitalization while concordance between a person's behavior and a caregiver's recommendations was considered as therapeutic compliance. For all participants, we measured height to the nearest $0.5 \mathrm{~cm}$, and weight in light clothing to the nearest $0.1 \mathrm{~kg}$, and calculated the body mass index (BMI) using Quetelet's index.

Therapeutic drug adherence was evaluated using the Morisky 8-items questionnaire [12], assessment of high blood pressure related knowledge was done with the Hypertension Knowledge Level Scale, while the quality of the diet was evaluated with the food evaluation questionnaire [13] [14], and the Karasek questionnaire (validated French version) was used to estimate the level of stress in professional environment [15].

Home BP were measured using an automated sphygmomanometer (Omron RS1, Omron Corporation, Tokyo, Japan). An armband was placed around the wrist with the arm slightly folded at the level of the elbow and resting on a table such that the cuff and the wrist is at the level of the heart. Measurements were performed on both hands by the participants after at least five minutes of rest, in a quiet place, and in the sitting position. Participants were not to move or talk during the measurement. The measures were repeated on the hand presenting the highest values of $\mathrm{BP}$, and the mean of the two measurements on this arm was considered and reported on the card. This was repeated twice a day (morning and evening) during three successive days of every week.

Energy expenditure related to physical activity was determined using a pedometer (Incutex). Before the beginning of physical exercise, the device was placed on the hip of each patient and was switched off at the end of the exercise. The 
patient was asked to report the type and duration of physical activity as well as data shown by the pedometer (number of steps, of kilocalories, and the distance). Assuming the recommendations of WHO, the following principles were applied: it was estimated that the caloric expenditure of a moderately active person was four times higher, and that of a person very active eight times higher than the caloric expenditure of a person sitting without moving. To calculate the total energy expenditure of a person using the data from the questionnaire, 2 METs (Metabolic Equivalent Task) were allocated to time spent in light-intensity physical activities, 4 METs to time spent on moderately intense physical activities and 8 METs time spent in intense physical activity. Total physical activity in MET-minutes/week = sum of MET-minutes corresponding to each situation [16].

\subsection{Statistical Analysis}

Data were analyzed using IBM SPSS Statistics for Windows, version 20.0. (Armonk, NY: IBM Corp). Results were presented as counts with percentage and means \pm SD and median (interquartile range) where adpated. The chi-squared test was used to test association between qualitative variables. The non-parametric Wilcoxon-test was used to compare data before and after intervention that was not normally distributed and the parametric paired t-test to compare data between normally distributed variables respectively between study groups. A two-tailed $p$ value $<0.05$ was considered statistically significant.

\section{Results}

\subsection{Participants' Characteristics}

Out of the 50 eligible patients, 20 refused to participate and 30 patients started the intervention. At the end, a total of 17 participants (09 women) completed the study after thirteen patients dropped out during the follow-up and one was excluded due to an acute complication of high blood pressure (Figure 1). The mean age of participants was $56.2 \pm 8.1$ years. Most of the participants were in the 60 - 65 years' age group. The average duration of hypertension was $11.2 \pm 9$ years. At baseline, the mean office systolic and diastolic blood pressure were 168 $\pm 26 \mathrm{~mm} \mathrm{Hg}$ and $97 \pm 11 \mathrm{~mm} \mathrm{Hg}$, respectively. Stroke was the most common complication (4/17), dual therapy the most commonly used therapeutic regimen (9/17), and occupational stress was reported by 1 out of 8 patients who were active participants.

\subsection{Therapeutic Adherence before and after Intervention}

After therapeutic education, the level of compliance increased from low-to-high for most participants-an improvement of $88.2 \%$. On the other hand, the compliance score increased by 3.51 points/8-an improvement of $81.4 \%$ (Table 1 ).

\subsection{Home Blood Pressure Values Control before and after}

This intervention was carried out in uncontrolled hypertensive patients with BP 


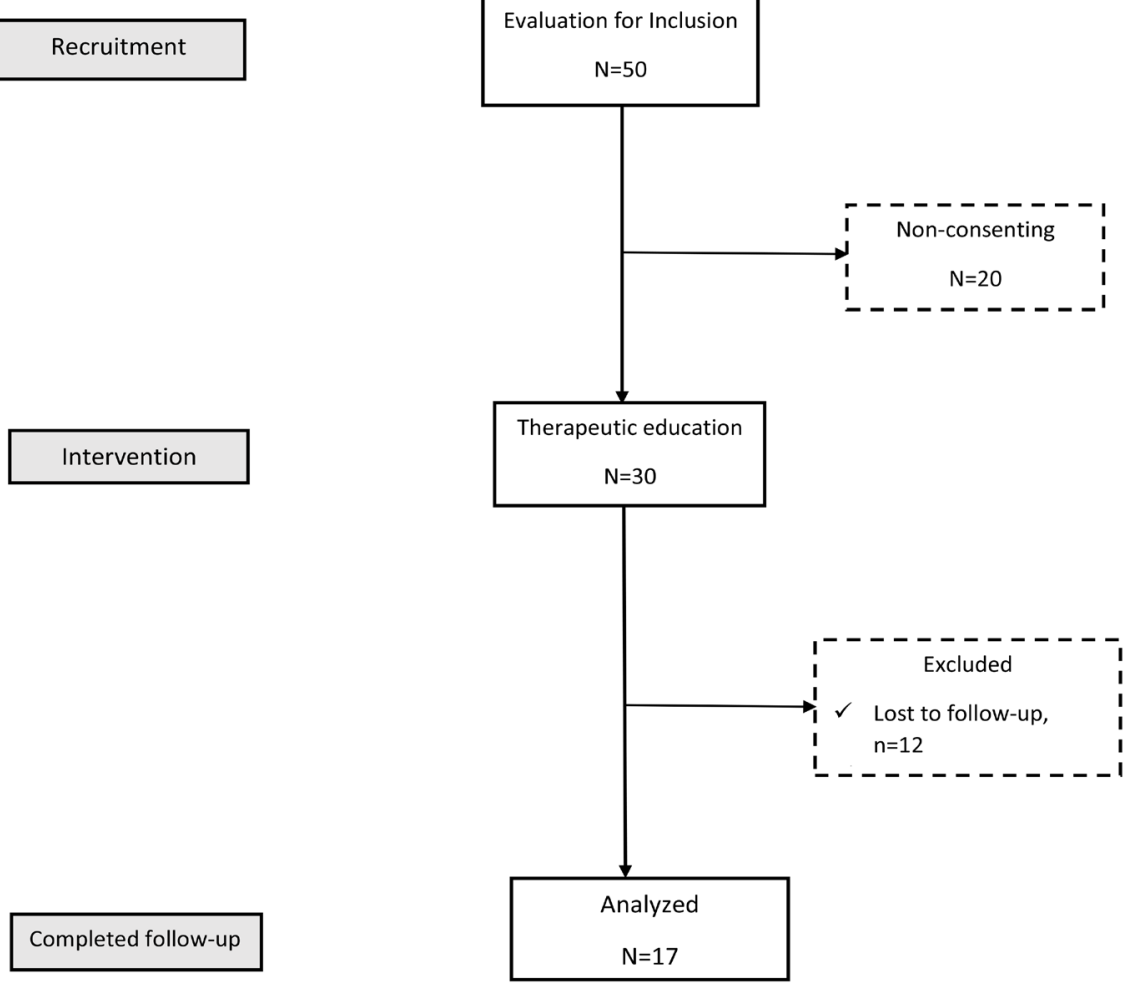

Figure 1. Flow of study participants.

Table 1. Comparisons of medians (interquartile range) before and after.

\begin{tabular}{cccccc}
\hline Variable & $\begin{array}{c}\text { Before } \\
(\mathrm{n}=17)\end{array}$ & After $(\mathrm{n}=17)$ & Variations & $\begin{array}{c}\text { Percentage } \\
\text { change }(\%)\end{array}$ & $p$ value \\
\hline $\begin{array}{c}\text { Morisky's score } \\
\text { Systolic blood pressure } \\
\quad \text { (mm Hg) }\end{array}$ & $15.3(1.9)$ & $7.8(0.5)$ & +3.5 & +81.4 & $<0.001$ \\
$\begin{array}{c}\text { Diastolic blood pressure } \\
(\text { mm Hg) }\end{array}$ & $90.8(9.2)$ & $79.3(7.6)$ & -11.5 & -12.7 & 0.01 \\
$\begin{array}{c}\text { Knowledge's score } \\
\text { Energy expenditure } \\
\quad \text { (METs) }\end{array}$ & $15.8(3.5)$ & $21.6(0.6)$ & +5.8 & +36.5 & $<0.001$ \\
$\begin{array}{c}\text { Alcohol consumption } \\
\text { (glasses/week) }\end{array}$ & $1.5(2.6)$ & $0.5(1.2)$ & -0.98 & -64.5 & 0.001 \\
$\quad$ Diet quality & $11.5(4.7)$ & $18.5(3.4)$ & +6.9 & +60.2 & $<0.001$ \\
\hline
\end{tabular}

MET: Metabolic Equivalent Task.

figures above targets. The variation of the systolic blood pressure from the beginning to the end of the intervention is presented in Table 1. Therapeutic education significantly improved SBP from $152 \mathrm{mmHg}$ initially to $122 \mathrm{mmHg}$ at the end. This results in an average decrease of $30 \mathrm{mmHg}$ of systolic BP amongst participants. At the end of the intervention, $88.2 \%$ of patients were controlled and reached the target figures for their BP control. On the other hand, diastolic BP varied from $90 \mathrm{mmHg}$ to $79 \mathrm{mmHg}$ decreasing by 11 $\mathrm{mmHg}$ (Figure 2). 


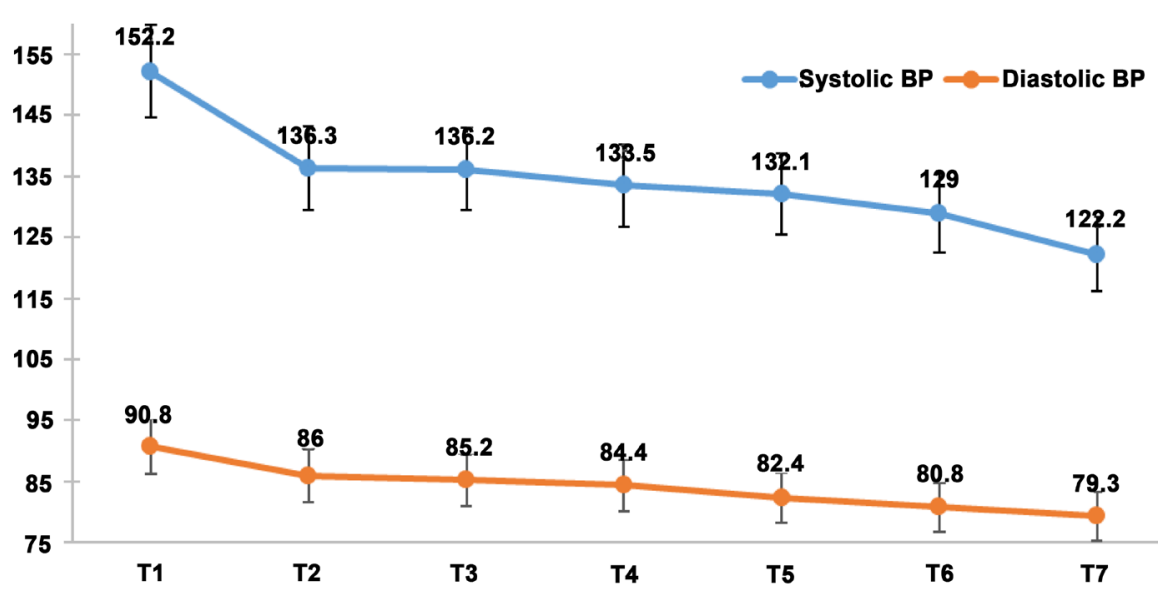

Figure 2. Evolutive profile of Systolic and Diastolic Blood pressures over time ( $\mathrm{T}$ in weeks).

\subsection{Knowledge of Participants Concerning High BP before and after Intervention}

Knowledge of participants on BP and related complications increased by 5.77 points/22-an improvement of $36.5 \%$ (Table 1 ).

\subsection{Physical Activity before and after Intervention}

Similarly, the intervention results in a significant improvement in energy expenditure related to physical activity, with an increase of 625.41 MET, giving an improvement of $185.2 \%$ (Table 1 ). The level of physical activity rated as poor at the beginning of the intervention passed to moderate at the end of the intervention (Figure 3).

\subsection{Alcohol Consumption and Quality of Diet before and after Intervention}

Concerning the consumption of alcohol: it decreased by 0.98 glasses/week-a reduction of $64.5 \%$. The quality of the diet classified as medium before intervention passed to very good for $52.9 \%$ of the participants at the end. The mean score increased by 6.94 points/43, a statistically significant variation of $60.19 \%$ (Table 1 ).

\subsection{Assessment of Patient Satisfaction}

At the end of intervention, all patients were satisfied by the lessons learned and acknowledged that lectures were adapted to their comprehension.

\section{Discussion}

This study was designed to evaluate the effect of a three months' program of therapeutic group education on therapeutic adherence and blood pressure control in uncontrolled hypertensive patients in sub Saharan Africa. We found that group patient education resulted in great increase of patient's knowledge, therapeutic adherence and physical activity levels resulting in a marked reduction of 


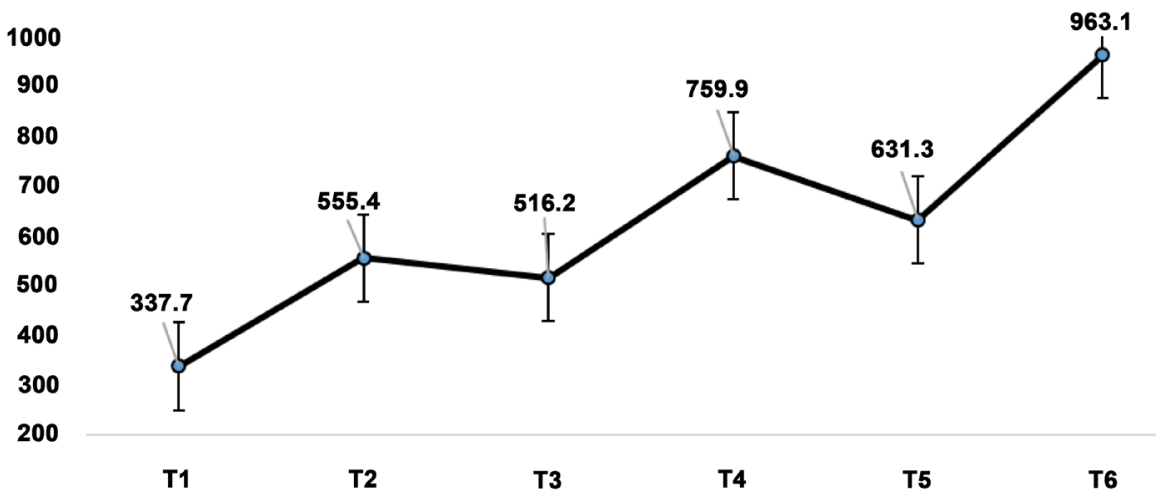

Figure 3. Evolutive profile of energy expenditure related to physical activity over time (T in weeks).

blood pressure figures, and significant improvement of blood pressure control in these individuals without any change in their medications.

Therapeutic education carried out during the study contributed to improve patient's knowledge regarding the disease, its complications and the importance of management measures currently prescribed. We obtained a significant difference between the pre- and post-intervention knowledge scores on the Hypertension Knowledge-Level Scale (HK-LS). This significant improvement of knowledge regarding the disease is of great importance considering the low level of knowledge exhibited by most of the participants at baseline and the low awareness on hypertension. Akoko et al., reported in their study published in 2015 only $14 \%$ of good knowledge amongst hypertensive patients in Cameroon [17]. The consequence of this situation in our context is the patient's difficulties to accept the necessity of lifelong treatment in the absence of obvious symptoms and the cost of certain drugs resulting to low adherence of patients and non-compliance. A factor that could explain this lack of knowledge is low literacy concerning chronic diseases such as high blood pressure and treatment modalities in a context where acute conditions and communicable diseases are still considered as the major health threats by most individuals and even policy makers. Therefore, integrating the concept of chronic conditions despite the absence of symptoms leading to an increase risk of life-threatening complications is a challenge for most patients. This requires an important therapeutic education by physician in daily practice for a better understanding of the condition by patients. However, the limited human resources in sub Saharan Africa, with the resultant high patients-to-physician ratio results in shorter consultation times, which can be insufficient to explain and discuss all the aspects of therapeutic education with patients [18]. This stresses the high needs in therapeutic education in our context of low literacy. But given the difficulties to achieve a good level of therapeutic education in outpatient clinics, therapeutic group education as implemented in this study could be an alternative to improve patient's knowledge in limited resources settings of sub Saharan Africa. A multidisciplinary 
approach and the development of education programs like ours that focused on promoting patient knowledge should be considered as important elements to integrate in the management of uncontrolled hypertensive patients in sub Saharan Africa.

Therapeutic adherence evaluated using the Morisky questionnaire was also low for most participants at baseline with the main reason of non-adherence to drugs medication being oblivion in more than three quarters of patients (82\%). Our intervention resulted in a significant improvement in the mean adherence score of $81.4 \%$ after three months of intervention. Similarly, Bosworth et al. In the United States in 2008 achieved a significant improvement in adherence using education and phone calls [19]. However, improvement was more important in our study certainly due to the addition of daily text messages and phone calls to the therapeutic education sessions. By increasing awareness of patients on the importance of their drug therapy, the intervention significantly improved adherence. This is consistent with findings of Ikama et al. in Congo in 2013 who found that call reminders was associated with better medication adherence [20]. Given the fact that therapeutic adherence is worse in limited resources settings [21], interventions such as phone reminders by calls or text messages that have been proven effective in communicable diseases such as HIV and tuberculosis could be cost effective, and should be adopted by non-communicable diseases clinics in order to improve therapeutic adherence of patients [22] [23] [24].

Our study also evaluated the difference in physical activity levels before and after intervention using pedometers. We found a significant increase in energy expenditure in $100 \%$ of our population study which is by far superior to findings of previous interventions conducted over a much longer period in developed countries [25] [26]. This is in agreement with previous findings which showed that short term interventions like ours usually results in greater effect than long term interventions. This marked improvement can also be attributed to the fact that at baseline, most of patients ignored the place and importance of physical activity on blood pressure control in our study. Therefore, increase in patient's knowledge has been associated with increase in physical activity in all participants.

Improvement in therapeutic adherence and physical activity level resulted in a marked reduction of home blood pressure figures in our study population. Systolic blood pressure decreased by $30 \mathrm{mmHg}$ while diastolic blood pressure decreased by $11 \mathrm{mmHg}$. Our findings are twice to six times greater than those of Cappucio et al., in 2005 in Ghana, who did not achieve $5 \mathrm{mmHg}$ of BP reduction on each component in a randomized clinical trial [27]. This could be due to the fact that we used home BP measures to evaluate BP control in our study while others studies used office BP measures. However, this improvement in BP control remained greater than the effect of any anti-hypertensive treatment currently used. Considering the cost of pharmacological treatment in our context [28], and the absence of health insurance, these findings stresses the importance of therapeutic education for uncontrolled hypertensive individuals in sub Saharan 
Africa. Physicians should make every effort to improve therapeutic education when facing uncontrolled hypertensive patients before adjunction of another pharmacological treatment to the currently used regimen. Also, given the outstanding results of such interventions, it should be considered by cardiovascular clinics in sub Saharan Africa as an effective method to reduce the burden of cardiovascular diseases.

The present study has some limitations that need to be highlighted. Despite the fact that the sample size was calculated in order to detect any existing effect, the small sample size of our study could be an impediment for the generalization of these results. Another limitation of this study was the absence of a control group that could allow a better quantification of the real effect of our intervention. Also, the short duration of the study could be a limitation since most studies using such interventions usually found greater improvements during the first weeks of the study, but these results tend to be reduced with time. Therefore, the important effects found in our study should serve as base for the design of randomized controlled trials using therapeutic education as the main intervention, with a larger sample size, and longer follow-up to generalize our results to the entire population.

This study revealed that therapeutic group education of uncontrolled hypertensive patients in sub-Sahara Africa improved adherence to therapeutic measures such as drug compliance and physical activity resulting in a marked reduction of BP, and a great amelioration of BP control without adjunction of any additional molecule.

\section{Acknowledgements}

We gratefully acknowledge all the patients who have accepted to take part in this study.

\section{Conflict of Interest}

The authors have no conflict of interest to declare.

\section{Ethics Approval and Consent to Participate}

This study was performed in accordance with the Declaration of Helsinki. Approved was obtained from the Institutional Research Ethical Committee of Université des Montagnes (No. 2017/028/UdM/PR/CIE), and from the institutional review board of the Yaoundé Central Hospital of Cameroon. This project was also approved by the regional ethic committee of the central region of Cameroon (No.: 0551/CRERSHC/2016). All participants provided written informed consent.

\section{Authors' Contributions}

1) Study conception and design: CNNG, HGKD and SK;

2) Administrative support: None; 
3) Provision of study material or patients: CNNG, HGKD, SK;

4) Collection and assembly of data: CNNG, HGKD, GB, ATT;

5) Data analysis and interpretation: CNNG, HGDK, SK;

6) Manuscript writing: All authors;

7) Final approval of manuscript: All authors.

\section{References}

[1] WHO_DCO_WHD_2013.2_eng.pdf. http://apps.who.int/iris/bitstream/10665/79059/1/WHO_DCO_WHD_2013.2_eng. pdf

[2] Lim, S.S., Vos, T., Flaxman, A.D., Danaei, G., Shibuya, K., Adair-Rohani, H., et al. (2012) A Comparative Risk Assessment of Burden of Disease and Injury Attributable to 67 Risk Factors and Risk Factor Clusters in 21 Regions, 1990-2010: PubMed a Systematic Analysis for the Global Burden of Disease Study 2010. Lancet, 380, 2224-2260. https://doi.org/10.1016/S0140-6736(12)61766-8

[3] Danaei, G., Finucane, M.M., Lin, J.K., Singh, G.M., Paciorek, C.J., Cowan, M.J., et al. (2011) Global Burden of Metabolic Risk Factors of Chronic Diseases Collaborating Group (Blood Pressure). National, Regional, and Global Trends in Systolic Blood Pressure since 1980: Systematic Analysis of Health Examination Surveys and Epidemiological Studies with 786 Country-Years and 5.4 Million Participants. The Lancet, 377, 568-577. https://doi.org/10.1016/S0140-6736(10)62036-3

[4] Rahimi, K., Emdin, C.A. and MacMahon, S. (2015) The Epidemiology of Blood Pressure and Its Worldwide Management. Circulation Research, 116, 925-936. https://doi.org/10.1161/CIRCRESAHA.116.304723

[5] Gaziano, T., Bitton, A., Anand, S. and Milton, C. (2016) The Global Cost of Nonoptimal Blood Pressure.

[6] Lawes, C.M., Hoorn, S.V. and Rodgers, A. (2008) Global Burden of Blood-PressureRelated Disease, 2001. The Lancet, 371, 1513-1518. https://doi.org/10.1016/S0140-6736(08)60655-8

[7] Dzudie, A., Kengne, A.P., Muna, W.F.T., Ba, H., Menanga, A., Kouam, C.K., et al. (2012) Prevalence, Awareness, Treatment and Control of Hypertension in a Self-Selected Sub-Saharan African Urban Population: A Cross-Sectional Study. BMJ, 2, e001217. https://doi.org/10.1136/bmjopen-2012-001217

[8] Kengne, A.P. and Sanni Yaya, H. (2014) Bibliotheque numérique canadienne (Firme). Le défi de la prévention des maladies cardiovasculaires et ses perspectives en Afrique: Juguler le mal meurtrier et insidieux de l'hypertension artérielle. http://www.deslibris.ca/ID/447859

[9] James, P.A., Oparil, S., Carter, B.L., Cushman, W.C., Dennison-Himmelfarb, C., Handler, J., et al. (2014) Evidence-Based Guideline for the Management of High Blood Pressure in Adults: Report from the Panel Members Appointed to the Eighth Joint National Committee (JNC 8). JAMA, 311, 507-520. https://doi.org/10.1001/jama.2013.284427

[10] Whitley, E. and Ball, J. (2002) Statistics Review 4: Sample Size Calculations. Critical Care, 6, 335-341. https://doi.org/10.1186/cc1521

[11] Korb-Savoldelli, V., Gillaizeau, F., Pouchot, J., Lenain, E., Postel-Vinay, N., Plouin, P.-F., et al. (2012) Validation of a French Version of the 8-Item Morisky Medication Adherence Scale in Hypertensive Adults. Journal of Clinical Hypertension, 14, 429-434. https://doi.org/10.1111/j.1751-7176.2012.00634.x 
[12] Morisky, D.E., Ang, A., Krousel-Wood, M. and Ward, H.J. (2008) Predictive Validity of a Medication Adherence Measure in an Outpatient Setting. Journal of Clinical Hypertension, 10, 348-354. https://doi.org/10.1111/j.1751-7176.2008.07572.x

[13] Baliz Erkoc, S., Isikli, B., Metintas, S. and Kalyoncu, C. (2012) Hypertension Knowledge-Level Scale (HK-LS): A Study on Development, Validity and Reliability. International Journal of Environmental Research and Public Health, 9, 1018-1029. https://doi.org/10.3390/ijerph9031018

[14] Laviolle, B., Froger-Bompas, C., Guillo, P., Sevestre, A., Letellier, C., Pouchard, M., et al. (2005) Relative Validity and Reproducibility of a 14-Item Semi-Quantitative Food Frequency Questionnaire for Cardiovascular Prevention. European Journal of Cardiovascular Prevention \& Rehabilitation, 12, 587-595. https://doi.org/10.1097/00149831-200512000-00012

[15] Santos, K.O.B., de Araújo, T.M., Carvalho, F.M. and Karasek, R. (2017) The Job Content Questionnaire in Various Occupational Contexts: Applying a Latent Class Model. BMJ Open, 7, e013596. https://doi.org/10.1136/bmjopen-2016-013596

[16] World Health Organization (2017) Manuel de Surveillance STEPS de l'OMS. http://apps.who.int/iris/bitstream/10665/43483/1/9789242593839_fre.pdf

[17] Akoko, B.M., Fon, P.N., Ngu, R.C. and Ngu, K.B. (2017) Knowledge of Hypertension and Compliance with Therapy among Hypertensive Patients in the Bamenda Health District of Cameroon: A Cross-Sectional Study. Cardiology and Therapy, 6, 53-67. https://doi.org/10.1007/s40119-016-0079-x

[18] Cameroun-Médecins (par 1000 habitants)|Statistiques (2017) http://perspective.usherbrooke.ca/bilan/servlet/BMTendanceStatPays?langue=fr\&co $\underline{\text { dePays }=\text { CMR\&codeStat }=\text { SH.MED.PHYS.ZS\& } \operatorname{codeS} \text { tat } 2=\mathrm{x}}$

[19] Bosworth, H.B., Olsen, M.K., Neary, A., Orr, M., Grubber, J., Svetkey, L., et al. (2008) Take Control of Your Blood pressure (TCYB) Study: A Multifactorial Tailored Behavioral and Educational Intervention for Achieving Blood Pressure Control. Patient Education and Counseling, 70, 338-347. https://doi.org/10.1016/j.pec.2007.11.014

[20] Ikama, M.S., Nsitou, B.M., Loumouamou, M., Kimbally-Kaky, G. and Nkoua, J.L. (2013) L'observance médicamenteuse et ses facteurs dans un groupe d'hypertendus congolais. The Pan African Medical Journal, 15, 121.

http://www.ncbi.nlm.nih.gov/pmc/articles/PMC3830472/ https://doi.org/10.11604/pamj.2013.15.121.2435

[21] Ghozzi, H., Kassis, M., Hakim, A., Sahnoun, Z., Abderrahmen, A., Abbes, R., et al. (2010) Observance médicamenteuse chez un échantillon d'hypertendus dans la région de Sfax (Tunisie). Annales de Cardiologie et d'Angéiologie, 59, 131-137. https://doi.org/10.1016/j.ancard.2010.04.004

[22] Bigna, J.J.R., Noubiap, J.J.N., Kouanfack, C., Plottel, C.S. and Koulla-Shiro, S. (2014) Effect of Mobile Phone Reminders on Follow-Up Medical Care of Children Exposed to or Infected with HIV in Cameroon (MORE CARE): A Multicentre, Single-Blind, Factorial, Randomised Controlled Trial. The Lancet Infectious Diseases, 14, 600-608. https://doi.org/10.1016/S1473-3099(14)70741-8

[23] De Jongh, T., Gurol-Urganci, I., Vodopivec-Jamsek, V., Car, J. and Atun, R. (2012) Mobile Phone Messaging for Facilitating Self-Management of Long-Term Illnesses. Cochrane Database of Systematic Reviews, 12, CD007459. https://doi.org/10.1002/14651858.CD007459.pub2

[24] Goyal, K., Sehgal, A. and Sehgal, R. (2015) Automated Text Message Reminders to 
Promote Good Health. The Lancet Infectious Diseases, 15, 18-19. http://www.thelancet.com/journals/laninf/article/PIIS1473-3099(14)71030-8/fulltext https://doi.org/10.1016/S1473-3099(14)71030-8

[25] Hinderliter, A.L., Sherwood, A., Craighead, L.W., Lin, P.H., Watkins, L., Babyak, M.A., et al. (2014) The Long-Term Effects of Lifestyle Change on Blood Pressure: One-Year Follow-Up of the ENCORE Study. American Journal of Hypertension, 27, 734-741. https://doi.org/10.1093/ajh/hpt183

[26] Elmer, P.J., Obarzanek, E., Vollmer, W.M., Simons-Morton, D., Stevens, V.J., Young, D.R., PREMIER Collaborative Research Group, et al. (2006) Effects of Comprehensive Lifestyle Modification on Diet, Weight, Physical Fitness, and Blood Pressure Control: 18-Month Results of a Randomized Trial. Annals of Internal Medicine, 144, 485-495. https://doi.org/10.7326/0003-4819-144-7-200604040-00007

[27] Cappuccio, F.P., Kerry, S.M., Micah, F.B., Plange-Rhule, J. and Eastwood, J.B. (2006) A Community Programme to Reduce Salt Intake and Blood Pressure in Ghana [ISRCTN88789643]. BMC Public Health, 6, 13. https://doi.org/10.1186/1471-2458-6-13

[28] Tankeu, A.-T., MfeukeuKuate, L., NganouGnindjio, C.-N., Ankotché, A., Leye, A., OndoaBongha, H., et al. (2017) Spécificités de la prise en charge de l'hypertension artérielle chez le patient diabétique sub-saharien. Médecine Mal Métaboliques, 11, 148-154. https://doi.org/10.1016/S1957-2557(17)30035-4

\section{Abbreviations}

BMI: Body Mass Index;

BP: Blood Pressure;

HIV: Human Immunodeficiency Virus;

HK-LS: Hypertension Knowledge-Level Scale;

JNC: Joint National Committee;

MET: Metabolic Equivalent Task;

WHO: World Health Organization. 